\title{
Emotional, behavioral and social difficulties among children with type 1 diabetes mellitus
}

\author{
Eman S Ahmed ${ }^{1 *}$, Eman M. M. Monazea ${ }^{2}$, Amera E Abdel- El Naser ${ }^{3}$, Safaa A M Kotb ${ }^{4}$ \\ ${ }^{1}$ Pediatric Nursing, Faculty of Nursing, Assiut University, Egypt \\ ${ }^{2}$ Public Health department, Faculty of Medicine, Assiut University, Egypt \\ ${ }^{3}$ Pyschiatric Nursing, Faculty of Nursing, Assiut University, Egypt \\ ${ }^{4}$ Community Health Nursing, Faculty of Nursing, Assiut University, Egypt \\ *Corresponding author E-mail: emansayed44@aun.edu.eg, emansayed44@yahoo.com
}

\begin{abstract}
Background: Children and adolescents with diabetes are at a greater risk for emotional and behavioral problems.

Aim of the study was to assess behavioral, emotional and social difficulties of diabetic children and examine the association of these difficulties with demographic and disease related variables.

Subjects and method: A cross sectional study of 423 diabetic children attended Sidy Galal health insurance outpatient clinic in Assuit city - Egypt was conducted. A similar number of healthy children matched for age, sex and socioeconomic status were included in the study as a control group used for comparison. Strength and Difficulty Questionnaire (SDQ) was used as a screening tool. The SDQ is a screening instrument consisting of five separate 5-item subscales for emotional symptoms, conduct problems, hyperactivity-inattention, peer problems, and prosocial behavior.

Results: Most of diabetic children (92.9\%) were in the abnormal group of the total score compared to $20.6 \%$ of the controls. In all SDQ subscales except prosocial, diabetic children had significantly higher percentages of abnormal indices than in controls ( $p$ value $<0.001$ ). Emotional, hyperactivity and conduct problems were significantly associated with age and sex of the child. Prolonged duration of illness was significantly associated with peer relationship problems. Glycemic control was not a significant risk factor for any problem.

Conclusion: Many of diabetic children had behavioral and psychosocial problems. Age and sex of the child and duration of the disease were important determinants for these problems.

Recommendation: Diabetic children need to be screened by psychologist and social worker to identify and manage any behavioral or emotional problems.
\end{abstract}

Keywords: Behavioral; Children; Emotional; Social; Type 1 Diabetes.

\section{Introduction}

Type 1 diabetes mellitus (T1DM) is a lifelong metabolic disorder that is treated with a complex regimen of insulin injections, diet and exercise, and can greatly affect the lives of the diabetic children and their family (Orsillo \& Roemer, 2005). Egypt is on top of all the countries in the Middle East and North Africa (MENA), with a prevalence of diabetes $15.27 \%$ in adult and $12.6 \%$ under the age of 15 years (Soltesz et al. 2010, The International Diabetes Federation 2013).

Diabetes impacts the life style, personality and overall emotional and physical well-being of the child (Orsillo \& Roemer, 2005). Living with a chronic disease can increase the risk of experiencing psychological, emotional and behavioral difficulties. (Hysing et al. 2007, Pinquart \& Shen, 2011). Children with diabetes were more likely to experience behavioral problems than comparison groups (Reynolds \& Helgeson, 2011). They has a stigma of being ill, feeling to be different from others, and having to struggle against the general population's lack of knowledge and wrong ideas about diabetes (Rubio Zarzuela et al. 2010).

Chisholm (2003) stated that children with diabetes usually have great concerns about their illness and its effect on peer relations. In addition, Guthire et al. 2003 reported that peer support has been found important not only in adjusting to diabetes but also in controlling blood glucose.

A substantial research base developed over the past decades provides evidence for the significant role of psychosocial factors in the management of type 1 diabetes in children and adolescents (WINKLEYK et al. 2006 and Kakleas et al. 2009). Personal, family, or environmental conditions present before the onset of diabetes may compound the delicate balance needed to maintain good glycemic control. Therefore, there is a great need, especially at the time of initial diagnosis, to assess the developmental, behavioral, and psychosocial aspects of diabetic children and their families and support these aspects to prevent long term consequences related to poor management (Guthrie et al. 2003, Davidson et al. 2004).

For children and adolescents, there is a need to identify psychological disorders associated with diabetes and to intervene early to minimize its impact over the course of development. (Wherrett et al. 2013). However, the psychological aspect of the disease is often missed with whole/most of the emphasis given on the strict maintenance of blood glucose. Diabetic care providers especially nurses and health educators need to be trained and experienced with behavioral and emotional needs of diabetic children and adolescents to provide the support and useful problem solving strate- 
gies and plan intervention programs for diabetics and their families.

The aim of this study was to assess behavioral, emotional and social difficulties of diabetic children and examine the association of these difficulties with demographic and disease related variables.

\section{Subjects and method}

This cross sectional study was conducted on 423 children with type I diabetes attended Sidy Galal health insurance outpatient clinic in Assuit city - Upper Egypt during the year 2015. Egyptian health insurance provides free medical care for all children in kindergarten, primary, preparatory and secondary schools. At the start of the study, all children with diabetes were at least six months post-diagnosis, currently under insulin therapy and free of secondary disease complications (i.e., retinopathy, neuropathy, etc.) and other major medical diseases.

A similar number of non-diabetic children were included in the study comprising a control group used for comparison. They were recruited from kindergarten and the schools within the same area and matched with the diabetic children for age, gender and socioeconomic level. They were apparently healthy and free from major illnesses.

Data were collected by a semi structured questionnaire including socio-demographic variables such as age, sex, residence, education and occupation of the parents, income, family history of diabetes and disease-related variables such as age at onset of disease, duration of the disease, type and frequency of insulin injection, checking of blood glucose, diet control, physical activity, and regular clinic attendance for follow up. Last registered glycated hemoglobin level was obtained from patients' record. Patients were classified as either controlled (having $\mathrm{HbAlc}<7.5 \%$ and uncontrolled if having $\mathrm{HbAlc} \geq 7.5 \%$., Kim et al. 2015, ADA 2016).

Socio-economic condition of diabetic children was assessed using (Abd El-Twaab, 1998). It included four items; level of education of parents ( 8 items), family income (6 items), job of parents, life styles (3 items). Each item have one score the total score were divided into three classes as high, moderate and low classes. The researchers modified the item of income of social class according to the rate of inflation and increase to be conforming with recent income through comparing difference of the value of the golden pound at 1998 to that at 2015 and multiplying the rate of inflation to the scale.

Strengths and Difficulties Questionnaire (SDQ) was used to assess the emotional, behavioral and social difficulties among diabetic and non-diabetic children. SDQ is a brief 25 -item behavioral screening instrument consisting of five separate 5-item subscales that generate scores for emotional symptoms, conduct problems, hyperactivity-inattention, peer problems, and prosocial behavior (Goodman, 1997). It asks about 25 attributes comprise the 5 subscales: 1) Emotional symptoms (such as: worried, unhappy child nervousness, easily scared), 2) Conduct problems (such as: fights with others, lose of temper, lies and cheats, steals things, 3) Hyperactivity/inattention (such as: moves his body, easily distracted, fidgeting, finishing work, restless or cannot stay still for long), 4) Peer relationship problems (such as: loneliness, liked by other children, has at least one good friend, get on better with adult than children), 5) Pro-social behavior (such as: considerate of other people's feelings, helpful, kind to younger children, volunteer to help others). SDQ is a three-point scale; not true, somewhat true, and certainly true. A total difficulty score is calculated by summing the first four subscales and exclude the pro-social behavior subscale. Usually, the scores range from $0-40$. Scores are classified in three categories: normal (0-15), borderline (16-19), and abnormal (20-40). For the emotional symptoms subscale, the scores can be interpreted according to: normal $(0-5)$, borderline (6), and abnormal (7-10). For conduct problems subscale, the scores can be interpreted according to: normal $(0-3)$, borderline
(4), and abnormal (5-10). For the Hyperactivity-Inattention subscale, the scores can be interpreted according to: normal (0-5), borderline (6), and abnormal (7-10). For the Peer Problems subscale, the scores can be interpreted according to: normal (0-3), borderline (4-5), and abnormal (6-10). For the prosocial behavior subscale, the scores can be interpreted according to: normal (6$10)$, borderline (5), and abnormal (0-4).

SDQ has been widely used, and its reliability and validity have been established in several studies (Goodman 2001, Muris et al. 2003, Obel et al. 2004, Hawes \& Dadds 2004, Niclasen et al. 2012). We utilized the Arabic version of the SDQ in our study. It was proved to be valid by Almaqrami and Shuwail (2004). For this study, Cronbach's alpha was used to determine the internal consistency reliability of the total score of SDQ and it was 0.72 . The questionnaire was completed by interviewing the parents/ caregivers of children aged 4 to 10 years and older children completed a self-report version for 11-17 year olds.

An informal consent was obtained from children' caregivers for participation in the study. The study was approved from ethical scientific committee of Faculty of Nursing Assiut University. An official permission was obtained from the head of Sidy Galal health insurance outpatient clinic and ministry of education for healthy children.

\subsection{Statistical analysis}

Data analysis was carried out using SPSS software (version 16). Data were presented using descriptive statistics in the form of frequencies and percentages. Comparisons between diabetic children and controls were conducted using chi-square test. Bivariate and multivariate logistic regressions were performed to identify independent demographic and disease related variables that associated with behavioral and psychosocial problems. The dependent variables were diabetic children scored abnormal in each SDQ subscale. A 2 - tailed $\mathrm{p}<0.05$ was considered statistically significant.

\section{Results}

The study included 423 children and adolescents with type I diabetes. Their age ranged from 4-17 years; mean age was $12.4 \pm 3.6$, male patients represented $47.3 \%$. The study also included 423 healthy children matched with diabetics for age, sex and socioeconomic status.

Table (1) presents diabetic children's difficulty index score versus the control group. Most of diabetic children (92.9\%) were in the abnormal group of the total score compared to $20.6 \%$ of the controls. In all SDQ subscales except prosocial, diabetic children had significantly higher percentages of abnormal behavior than in controls $(\mathrm{P}<0.001)$

Table (2) demonstrates the relationship between some demographic and disease related variables with emotional, behavioral and social difficulties among diabetic children. The results show that emotional, hyperactivity and conduct problems were significantly associated with age and sex of the child, as they increased in older children and female children had higher percentage of hyperactivity and conduct problems but lower percentage of emotional problems than males $(68.6 \%, 71.7 \%, 57.4 \%$ vs. $58.0 \%, 62.0 \%, 68.0 \%$ respectively

Parent's educational level was significantly associated with peerrelationship, as children of mothers or fathers with high education level (secondary or above secondary) had higher percentages of peer problems. Also the results show that family history of diabetes was significantly associated with emotional problems, as children who had no family history of diabetes experienced emotional difficulties than those with positive family history $(64.3 \%$ vs. $50 \%, \mathrm{P} 0.040$ ). The table (2) also shows that emotional and peer difficulties were significantly high with the increased duration of diabetes $(\mathrm{P}<0.001)$. Glycemic control was only significantly associated with emotional and conduct problems. 
Table 1: Difficulty Index Score of Diabetic Children versus Non Diabetic Children

\begin{tabular}{|c|c|c|c|c|c|c|c|}
\hline \multirow[b]{2}{*}{$\begin{array}{l}\text { Difficulty Index } \\
\text { domain }\end{array}$} & \multicolumn{6}{|c|}{ Difficulty Index Score } & \multirow[b]{2}{*}{$P$ value } \\
\hline & $\begin{array}{l}\text { Normal } \\
\mathrm{n}(\%)\end{array}$ & $\begin{array}{l}\text { Borderline } \\
\mathrm{n}(\%)\end{array}$ & $\begin{array}{l}\text { Abnormal } \\
\mathrm{n}(\%)\end{array}$ & $\begin{array}{l}\text { Normal } \\
\mathrm{n}(\%)\end{array}$ & $\begin{array}{l}\text { Borderline } \\
\mathrm{n}(\%)\end{array}$ & $\begin{array}{l}\text { Abnormal } \\
\mathrm{n}(\%)\end{array}$ & \\
\hline Emotional & $117(27.7)$ & $42(9.9)$ & $264(62.4)$ & $255(60.3)$ & $68(16.1)$ & $100(23.6)$ & $<0.001$ \\
\hline Conduct & $98(23.2)$ & $41(9.7)$ & $284(67.1)$ & $278(65.7)$ & $24(5.7)$ & $121(28.6)$ & $<0.001$ \\
\hline Hyperactivity & $103(24.3)$ & $51(12.1)$ & $269(63.6)$ & $200(47.3)$ & $139(32.9)$ & $84(19.9)$ & $<0.001$ \\
\hline Peer & $48(11.3)$ & $27(6.4)$ & $348(82.3)$ & $253(59.8)$ & $43(10.2)$ & $127(30.0)$ & $<0.001$ \\
\hline Prosocial & $382(90.3)$ & $20(4.7)$ & $21(5.0)$ & $394(93.1)$ & $18(4.3)$ & 11(2.6) & 0.18 \\
\hline
\end{tabular}

Table 2: Factors Associated with Abnormal Difficulty Index Subscales

\begin{tabular}{|c|c|c|c|c|c|}
\hline Variables & $\begin{array}{l}\text { Number } \\
(423)\end{array}$ & $\begin{array}{l}\text { Difficulty index subscale } \\
\text { Emotional } \mathrm{n}(\%)\end{array}$ & Conduct n (\%) & Hyperactivity n (\%) & Peer n $(\%)$ \\
\hline \multicolumn{6}{|l|}{ Child's age/years } \\
\hline $4-<6$ & 30 & $8(26.7)$ & $9(30.0)$ & $12(40.0)$ & $23(76.7)$ \\
\hline$\geq 12$ & 229 & $150(65.5)$ & $167(72.9)$ & $155(67.7)$ & $182(79.5)$ \\
\hline$P$ value & & 0.000 & 0.000 & 0.011 & 0.100 \\
\hline \multicolumn{6}{|l|}{ Sex of the child } \\
\hline Male & 200 & $136(68.0)$ & $124(62.0)$ & $116(58.0)$ & $162(81.0)$ \\
\hline Female & 223 & $128(57.4)$ & $160(71.7)$ & $153(68.6)$ & $186(83.4$ \\
\hline$P$ value & & 0.025 & 0.033 & 0.024 & 0.517 \\
\hline \multicolumn{6}{|l|}{ Birth order } \\
\hline First & 75 & $50(66.7)$ & $57(76.0)$ & $55(73.3)$ & $62(82.7)$ \\
\hline Second & 108 & $67(62.0)$ & $67(62.0)$ & $69(63.9)$ & $92(85.2)$ \\
\hline Third & 240 & $147(61.2)$ & $160(66.7)$ & $145(60.4)$ & $194(80.8)$ \\
\hline$P$ value & & 0.697 & 0.138 & 0.127 & 0.614 \\
\hline \multicolumn{6}{|l|}{ Mother's education } \\
\hline Illiterate & 166 & $93(56.0)$ & $103(62.0)$ & $98(59.0)$ & $126(75.9)$ \\
\hline$\geq 12$ years & 175 & $107(61.1)$ & $117(66.9)$ & $111(63.4)$ & $154(88.0)$ \\
\hline $\bar{P}$ value & & 0.003 & 0.041 & 0.093 & 0.014 \\
\hline \multicolumn{6}{|l|}{ Father's education } \\
\hline Illiterate & 106 & $57(53.8)$ & $67(63.2)$ & $67(63.2)$ & $75(70.8)$ \\
\hline$<12$ years & 83 & $55(66.3)$ & $62(74.7)$ & $54(65.1)$ & $68(81.9)$ \\
\hline$\geq 12$ years & 234 & $152(65.0)$ & $155(66.2)$ & $148(63.2)$ & $205(87.6)$ \\
\hline$P$ value & & 0.103 & 0.226 & 0.953 & 0.001 \\
\hline \multicolumn{6}{|c|}{ Family history of diabetes } \\
\hline Yes & 56 & $28(50.0)$ & $40(71.4)$ & $36(64.3)$ & $49(87.5)$ \\
\hline No & 367 & $236(64.3)$ & $244(66.5)$ & $233(63.5)$ & $299(81.5)$ \\
\hline$P$ value & & 0.040 & 0.463 & 0.908 & 0.271 \\
\hline \multicolumn{6}{|c|}{ Duration of having diabetes/years } \\
\hline Less than 1 year & 54 & $19(35.2)$ & $32(59.3)$ & $32(59.3)$ & $45(83.3)$ \\
\hline From 1 to $<3$ & 107 & $68(63.6)$ & 69 & $65(60.7)$ & $76(71.0)$ \\
\hline From 3 to $<5$ & 141 & $96(68.1)$ & 96 & $88(62.4)$ & $120(85.1)$ \\
\hline$\geq 5$ & 121 & $81(66.9)$ & 87 & $84(69.4)$ & $107(88.4)$ \\
\hline $\mathrm{P}$ value & & 0.000 & 0.367 & 0.445 & 0.004 \\
\hline Uncontrolled & 266 & $155(58.3)$ & $166(62.4)$ & $161(60.5)$ & $222(83.5)$ \\
\hline $\mathrm{P}$ value & & 0.022 & 0.007 & 0.088 & 0.405 \\
\hline
\end{tabular}

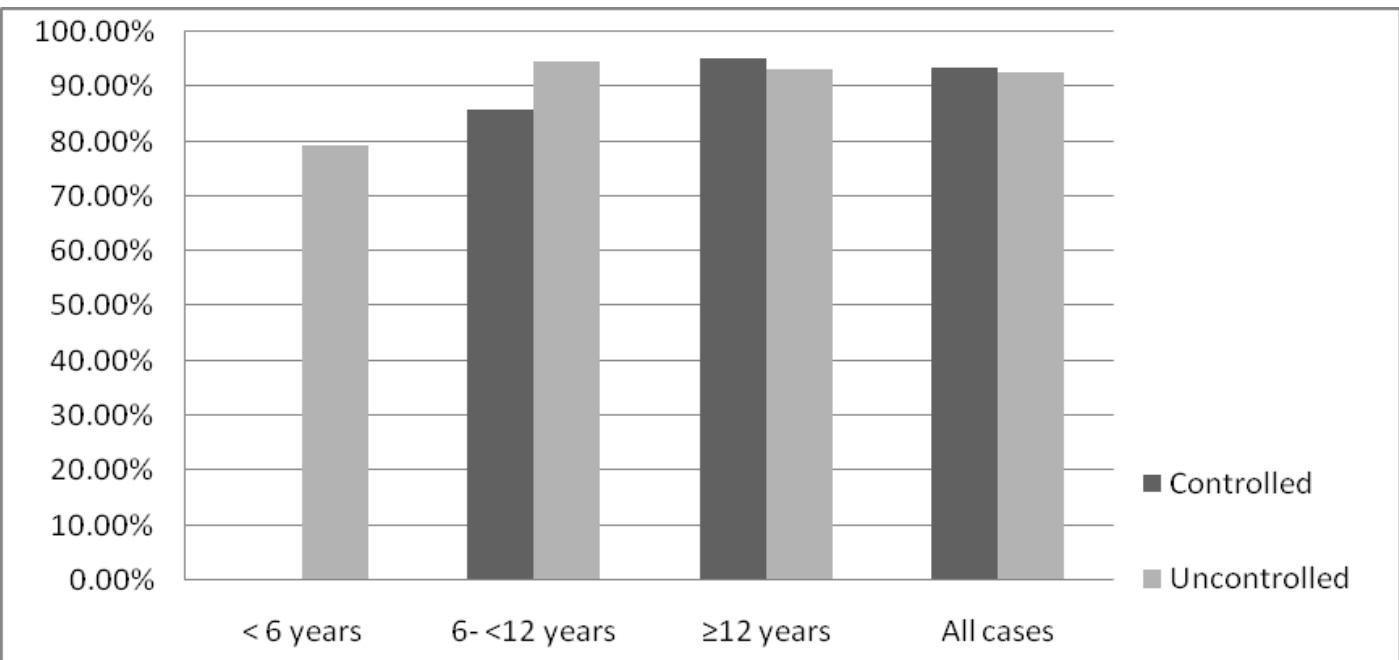

Fig. 1: Percent of Diabetic Children who had Abnormal Total Difficulty Index by Glycemic Control according to Their Age Group. 
Stratification of patients by age and glycemic control (figure 1) shows that although no one of diabetic children under 6 year of age with controlled glycemic level had abnormal total score, there were no significant differences between glycemic control and abnormal total difficulty score in different age groups.

Table 3: Determinants of Abnormal Difficulty Index Subscales by Logistic Regression

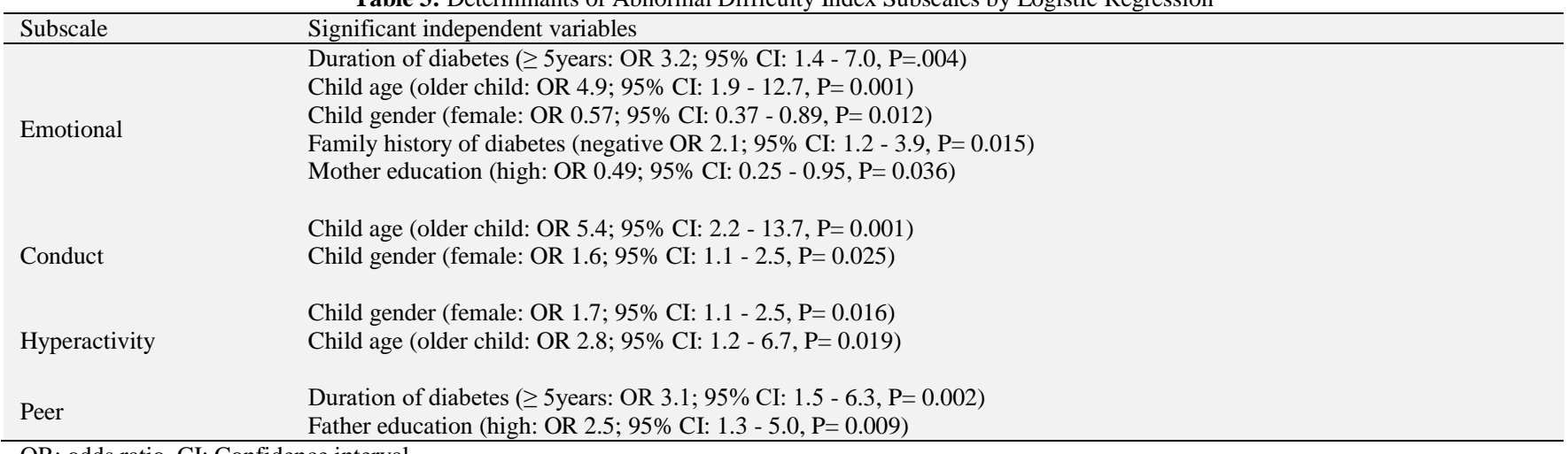

OR: odds ratio, CI: Confidence interval

In multivariate logistic analysis (Table 3 ) predictor of emotional problems were age and sex of the child, level of mother's education, family history of diabetes and duration of illness. For hyperactivity and conduct problems, the predictors were age and sex of the child. For peer relationship problems, duration of illness and education level of the child's father were independent significant factors.

\section{Discussion}

Type I diabetes as a chronic illness is an important factor causing psychological and behavioral difficulties in children (Hysing et al. 2009). This study was performed to assess the psychosocial and behavioral aspects of diabetic children and adolescents using SDQ as a screening instrument. The findings of the study indicated that most of diabetic children $(92.9 \%)$ had psychosocial and behavioral difficulties in the form of emotional, conduct, hyperactivity, and peer relationship problems in comparison to only $20.6 \%$ in normal children. Previous studies of Al-Khurinej, 2007; Kerry \& Vicki, 2011; Cho et al. 2013 and Kim et al. 2015 confirmed that diabetic children had considerable emotional and behavioral difficulties. Moreover, Kristensen et al. 2014 reported that diabetic children had significantly higher emotional and conduct problems compared to normal children. In their study McCarthy et al. (2002) also showed that diabetic children have more behavioral problems than their siblings. However some studies have found children and adolescents with diabetes to be similar to control groups of children and adolescents without diabetes regarding the prevalence of psychological difficulties (Grey et al. 1994, Helgeson et al. 2007). Results of this study showed that there was insignificant difference between diabetic children and normal children regarding prosocial difficulties $(5.0 \%$ vs. $2.6 \%, \mathrm{P} 0.18)$. This is in accordance with the finding of Al-Khurinej, 2007. This may be related to the nature of the people in Upper Egypt who are sociable, like helping others particularly those with disease and rearing their children on these characteristics.

Peer support has been found to be important not only in adjusting to diabetes but also in controlling blood glucose (Guthire et al. 2003). In this study peer relationship was the most negatively affected behavior in diabetic children; the percent of diabetic children who had peer problems was $82.3 \%$ with no sex or age significant differences. This result is in agreement with that of Chisholm (2003) who stated that children with diabetes usually have great concerns about their illness and its effect on peer relations. Diabetic children are easily fatigable compared to normal peers who are full of energy which make them feel different. Children with diabetes has a stigma of being ill, feeling to be different from others, and having to struggle against the general population's lack of knowledge and wrong ideas about diabetes (Rubio Zarzuela et al. 2010). Peer difficulties were significantly associated with duration of diabetes and educational level of the child's parents especially the fathers $(\mathrm{P}<0.01)$. Educated parents may be more restricted with their children which had a negative impact on their peer relationship. As the duration of illness increased, diabetics take the responsibility of managing their disease and feel of inadequacy which leads to restriction of their activities and withdrawal (Yousef 1993, Chisholm 2003). However, Mounir and Abolfotouh 2005 found that $65.3 \%$ of diabetic children had a very good relationship to their friends with no significant sex difference. The difference may be related to different measuring tool used in their study.

Our results revealed that approximately two thirds of diabetic children had emotional symptoms and/ or hyperactivity or conduct problems. Age and gender of the child were significantly associated with these problems. Older children had higher percentages of emotional and behavioral difficulties. Female children had higher odds for hyperactivity and conduct problems (OR 1.7; 95\% CI: $1.1-2.5, \mathrm{P}=0.016$, OR 1.6; 95\% CI: $1.1-2.5, \mathrm{P}=0.025$, respectively) but lower odds for emotional problems than males (OR $0.57 ; 95 \%$ CI: $0.37-0.89, \mathrm{P}=0.012$ ). It was reported that psychiatric disorders are more prevalent among adolescents with type I diabetes (Blanz et al, 1993) and the majority of our studied children were in the pre-pubertal and adolescence stage. In this stage the children are characterized by their obstinacy, depressive mood and rule breaking behavior and diminished parental control as youngest children.

Mounir and Abolfotouh 2005 found that more females had stress symptoms than males ( $35.8 \%$ vs. $26.1 \%$ ) but the difference wasn't statistically significant. Female patients are more likely to have depression, anxiety or low self-esteem (Hood 2006). Other researchers reported that girls have more support than boys for diabetic control and emotional problems which may be attributed to more intimate nature of female compared with male friendship (Beaman, 2002, Pendley et al. 2002).

Previous studies revealed that good glycemic control depends on a healthy psychological environment. Likewise, psychological wellbeing is affected by glycemic control (Canadian Diabetes Association, 2003, Guthrie et al. 2003). Gaudieri et al., 2008 found that most of diabetic children with hyperactivity had uncontrolled glycemic condition, which in turns had its impact on cognitive function as attention and psychomotor efficiency. About two thirds of our diabetic children had uncontrolled glycemic level, however, there was no significant association between glycemic control and emotional and behavioral problems. Kim et al. 2015 reported similar findings. However, our results conflicted with Schaajk et al. 2013 who stated that children with poor blood glucose regulation experienced emotional and social difficulties. In an effort to explain this result, most of studied children had uncontrolled glycemic level and were in the pre-pubertal and adolescence stage where adherence difficulties with diabetes management peak and metabolic control deteriorates (Hamilton and Daneman 2002). 
More emphasis may be given on the strict maintenance of blood glucose on the expense of the psychological aspect of the disease. In conclusion, peer, conduct, hyperactivity and emotional problems are more prevalent among diabetic children. Older children, females and prolonged duration of diabetes were significant independent factors associated with these problems. Recommendations: Diabetic children need to be screened and assessed by psychologist and social worker for early detection of any behavioral and psychological difficulties. Diabetic care providers especially nurses should be trained and experienced on the educational, behavioral, and emotional needs of diabetic children and their parents to offer them the psychosocial support from the onset of diabetes and regularly thereafter.

\section{References}

[1] Abd El-Tawb (1998): Socio-economic scale, Faculty of Education, Assiut University.

[2] ADA (American Diabetes Association): Children and Adolescents, $\begin{array}{llll}\text { Diabetes Care 2016;39(Suppl. } & \text { 1):S86 S93 }\end{array}$ https://doi.org/10.2337/dc16-S014

[3] Al-Khurinej, A. (2007), Emotional and Behavioral Problems among Diabetic Children. Digest of Middle East Studies, 16 (1): 1-11. https://doi.org/10.1111/j.1949-3606.2007.tb00061.x.

[4] Almaqrami, M., Shuwail, A. (2004). "Validity of the Self-report Version of the Strengths and Difficulties Questionnaire in Yemen". Saudi Medical Journal, 25(5); 592-601.

[5] Bearman KJ, LaGreca AM. Assessing friend support of adolescents' diabetes care: The Diabetes Social Support Questionnaire- friends version, J Pediatr Psychol 2002; 27: 417- 28 . https://doi.org/10.1093/jpepsy/27.5.417.

[6] Blanz B, Rensch-Riemann B, Fritz-Sigmund D \& Schmidt M. Iddm Is A Risk Factor For Adolescent Psychiatric Disorders. Diabetes Care 1993: $\quad 16$ : 1579-1587. https://doi.org/10.2337/diacare.16.12.1579.

[7] Canadian Diabetes Association, Clinical Practice Guidelines Expert Committee. Canadian Diabetes Association 2003 clinical practice guidelines for the prevention and management of diabetes in Canada. Can J Diabetes 2003; 27(Suppl 2):S50-2, 84-90.

[8] Chisholm, V. (2003). "The Adjustment to Diabetes of School-age Children with Psychological Adjustment Problems". British Journal of Health Psychology, 8; 335-358. https://doi.org/10.1348/135910703322370897.

[9] Cho E, Shin SH, Eun SH, Kim JY, Nam HK, et al. (2013) Psychological characteristics of Korean children and adolescents with type 1 diabetes mellitus. Ann Pediatr Endocrinol Metab 18: 122-127. https://doi.org/10.6065/apem.2013.18.3.122.

[10] Davidson M. Effect of nurse-directed diabetes care in a minority population. Diabetes Care 2003; 26(8): 2281-87. https://doi.org/10.2337/diacare.26.8.2281.

[11] Gaudieri AP \& GREER TF (2008): Cognitive Function in Children with Type 1Diabetes. Diabetes Care, 31(9):1892-1897. https://doi.org/10.2337/dc07-2132.

[12] Goodman R. The Strengths and Difficulties Questionnaire: a research note. J Child Psychol Psychiatry.1997; 38:581-586. https://doi.org/10.1111/j.1469-7610.1997.tb01545.x.

[13] Goodman R (2001) Psychometric properties of the strengths and difficulties questionnaire. J Am Acad Child Adolesc Psychiatry 40: 1337-1345. https://doi.org/10.1097/00004583-200111000-00015.

[14] Grey M, Cameron ME, Lipman TH, Thurber FW (1994) Initial adaptation in children with newly diagnosed diabetes and healthy children. Pediatr Nurs 20: 17-22.

[15] Guthrie DW, Bartsocas C, Jarosz-Chabot P, Konstantinova M. Psychosocial issues for children and adolescents with diabetes: Overview and recommendations. Diabetes Spectr 2003; 16:7-12. https://doi.org/10.2337/diaspect.16.1.7.

[16] Helgeson VS, Snyder PR, Escobar O, Siminerio L, Becker D (2007) Comparison of adolescents with and without diabetes on indices of psychosocial functioning for three years. J Pediatr Psychol 32: 794-806. https://doi.org/10.1093/jpepsy/jsm020.

[17] Hamilton, J. \& Daneman, D. (2002) 'Deteriorating Diabetes Control during Adolescence: Physiological or Psychosocial?' Journal of Pediatric Endocrinology \& Metabolism [online] 15, (2) 115-126 https://doi.org/10.1515/JPEM.2002.15.2.115.

[18] Hawes, D.J., Dadds, M.R. (2004). "Australian Data and Psychometric Properties of the Strengths and Difficulties Questionnaire". Aus- tralian and New Zealand Journal of Psychiatry, 38; 644-651. https://doi.org/10.1080/j.1440-1614.2004.01427.x.

[19] Hood KK, Huestis S, Maher A, Butler D, Volkening L, et al. (2006) Depressive Symptoms in Children and Adolescents with Type 1 Diabetes: Association with diabetes-specific characteristics. Diabetes Care 29: 1389-139 https://doi.org/10.2337/dc06-0087.

[20] Hysing M, Elgen I, Gillberg C, Lie SA, Lundervold AJ (2007) Chronic physical illness and mental health in children. Results from a large-scale population study. J Child Psychol Psychiatry 48: 785792. https://doi.org/10.1111/j.1469-7610.2007.01755.x.

[21] Hysing ME, Elgen I, Gillberg c, Lum-dervold A. (2009): Emotional and behavioral problems in subgroups of children with chronic illness: results from a large - scale population study. Child care, Health and development, 35 (4); $527 \quad-533$ https://doi.org/10.1111/j.1365-2214.2009.00967.x.

[22] International Diabetes Federation (2013) IDF Diabetes Atlas 6th Edition. Available at: http://www.idf.org/sites/default/ files/EN_6E_Atlas_Full_0.pdf (accessed 8 October 2014).

[23] Kakleas K, Kandyla B, Karayianni C, Karavanaki K. Psychosocial problems in adolescents with type 1 diabetes mellitus. Diabetes Metab 2009; 35:339-50 https://doi.org/10.1016/j.diabet.2009.05.002.

[24] Kerry AR, Vicki SH (2011) Children with diabetes compared to peers: depressed? Distressed? A meta-analytic review. Ann Behav Med 42: 29-41 https://doi.org/10.1007/s12160-011-9262-4.

[25] kim W, Hong JP, and Ho Yoo J::(2015): Emotional and Behaviora Problems and Glycemic Control in Adolescents with Type 1 and Type 2 Diabetes. Journal of Psychiatry, 18 (2):1-5.

[26] Kristensen LJ, Birkebaek NH, Mose AH, Hohwu" L, Thastum M (2014) Symptoms of Emotional, Behavioral, and Social Difficulties in the Danish Population of Children and Adolescents with Type 1 Diabetes - Results of a National Survey. PLoS ONE 9(5): e97543. https://doi.org/10.1371/journal.pone.0097543.

[27] McCarthy, A., Lindgren, S., Mengeling, M., Tsalikian, E., and Engvall, J. (2002). "Effects of Diabetes on Learning in Children". Pediatrics, 109(1); E9. https://doi.org/10.1542/peds.109.1.e9.

[28] Mounir GM, Abolfotouh MA. Psychosocial characteristics of diabetic students at sporting student hospital in Alexandria. J Egypt Public Health Assoc. 2005; 80:475-93.

[29] Muris, P., Meesters, C., van den Berg, F. (2003). "The Strengths and Difficulties Questionnaire (SDQ): Further Evidence for its Reliability and Validity in a Community Sample of Dutch Children and Adolescents". European Child and Adolescent Psychiatry, 12; 1-8. https://doi.org/10.1007/s00787-003-0298-2.

[30] Niclasen J, Teasdale TW, Andersen AM, Skovgaard AM, Elberling $\mathrm{H}$, et al. (2012) Psychometric properties of the Danish Strength and Difficulties Questionnaire: the SDQ assessed for more than 70,000 raters in four different cohorts. PLoS One 7: e32025. https://doi.org/10.1371/journal.pone.0032025.

[31] Obel C, Heiervang E, Rodriguez A, Heyerdahl S, Smedje H, et al (2004) The Strengths and Difficulties Questionnaire in the Nordic countries. Eur Child Adolesc Psychiatry 13 Suppl 2: II32-II39. https://doi.org/10.1007/s00787-004-2006-2.

[32] Orsillo, S. M., \& Roemer, L. (Eds.). (2005). Acceptance and mindfulness-based approaches to anxiety: New directions in conceptualization and treatment. New York: Kluwer Academic/Plenum (Springer). https://doi.org/10.1007/b136521.

[33] Pendley JS, Kasmen LJ, Miller DL, Donze J, Swenson C, Reeves G. Peer and family support in children and adolescents with type I diabetes. J Pediatr Psychol 2002; 27: 429- 38 . https://doi.org/10.1093/jpepsy/27.5.429.

[34] Pinquart M, Shen Y (2011) Depressive Symptoms in Children and Adolescents with Chronic Physical Illness: An Updated MetaAnalysis. J Pediatr Psychol 36: 375-384. https://doi.org/10.1093/jpepsy/jsq104.

[35] Reynolds KA, Helgeson VS (2011) Children with diabetes compared to peers: depressed? Distressed? A meta-analytic review. Ann Behav Med 42: 29-41. https://doi.org/10.1007/s12160-011-9262-4.

[36] Rubio Zarzuela E, San Gregorio AP, Conde Hernamdez J. (2010): behavioral and emotional differences in groups of child and juvenile chronic patients. Annuary of clinical and health psychology, 6 : 21- 31

[37] Schaaijk MN, Roeleveld-Versteegh BA, Odink RR and van Baar LA (2013): Behavioral Problems and Depressive Symptoms in Adolescents with Type 1 Diabetes Mellitus: Self and Parent Reports. Diabetes Mellitus - Insights and Perspectives. This is an open access chapter distributed under the terms of the Creative Commons Attribution License http://creativecommons.org/licenses/by/3.0), 47-58. https://doi.org/10.5772/50667. 
[38] Soltesz G, Patterson C, Dahlquist G. Global trends in childhood type 1 diabetes. IDF Diabetes Atlas, 4 th ed.; 2010. p. 1-36. Available

from:

Http://www.idf.org/sites/default/files/Diabetes_in_the_Young.pdf [Last accessed on 2012 Mar 7].

[39] Wherrett D, Huot C, Mitchell B et al. Type 1 Diabetes in Children and Adolescents. Canadian Journal of Diabetes; 37 (2013) S153S162. https://doi.org/10.1016/j.jcjd.2013.01.042.

[40] WINKLEYK, LANDAUS, EISLERI, ISMAILK. Psychologica interventions to improve glycaemic control in patients with type 1 diabetes: systematic review and meta-analysis of randomized controlled trials. BMJ 2006: 333: $65-68$. https://doi.org/10.1136/bmj.38874.652569.55.

[41] Yousef, J. (1993). "Meeting the Counseling needs of Children with Diabetes". International Journal for the Advancement of Counseling, 16; 29-36. https://doi.org/10.1007/BF01418181. 